\title{
Publisher Correction: Forms of prediction in the nervous system
}

\section{Christoph Teufel (D) and Paul C. Fletcher (D)}

Nature Reviews Neuroscience (2020) https://doi.org/10.1038/s41583-020-0275-5 Published online 10 March 2020

In the originally published article, there was an error in the colour key shown in part $\mathbf{g}$ of Figure 2 . This should have indicated that the blue lines represent observer performance before receipt of prior object knowledge, whereas the red lines represent observer performance after receipt of prior object knowledge. This has been corrected in the HTML and PDF versions of the article.

https://doi.org/10.1038/s41583-020-0296-0 I Published online 27 March 2020

๑) Springer Nature Limited 2020

$\mathbf{g}$

\section{Original}
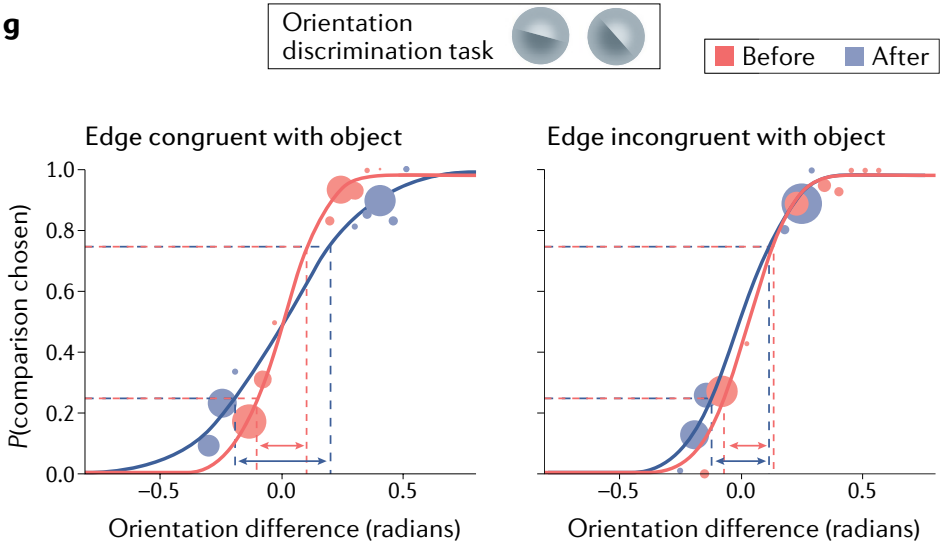

Edge incongruent with object

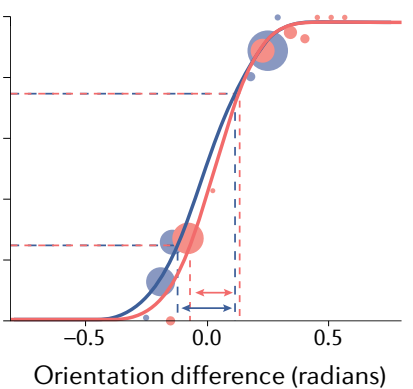

Corrected

$\mathbf{g}$
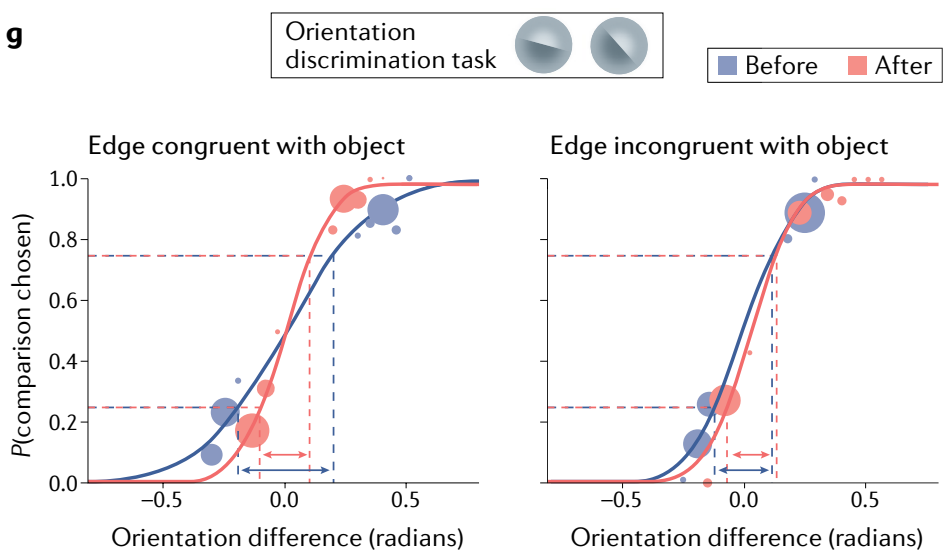

\section{Publisher Correction: An integrative framework for perceptual disturbances in psychosis}

\section{Guillermo Horga and Anissa Abi-Dargham (D)}

Nature Reviews Neuroscience (2019) https://doi.org/10.1038/s41583-019-0234-1 Published online 11 November 2019

In this Review Article, the accept date was inadvertently omitted. It should be 9 October 2019. This error has been corrected online.

https://doi.org/10.1038/s41583-020-0290-6 I Published online 10 March 2020

(๑) Springer Nature Limited 2020 